\title{
AN INTEGRATED FUZZY ANP-QFD APPROACH FOR GREEN BUILDING ASSESSMENT
}

\author{
Joshua IGNATIUS ${ }^{\mathrm{a}}$, Amirah RAHMAN ${ }^{\mathrm{a}}$, Morteza YAZDANI ${ }^{\mathrm{b}}$, Jonas ŠAPARAUSKAS ${ }^{\mathrm{c}}$, \\ Syarmila Hany HARON ${ }^{\mathrm{d}}$ \\ ${ }^{a}$ School of Mathematical Sciences, Universiti Sains Malaysia, 11800 Minden, Penang, Malaysia \\ ${ }^{b}$ Department of Business Management, Faculty of Social Science, Universidad Europea de Madrid, \\ 28670, Madrid, Spain \\ ${ }^{c}$ Department of Construction Technology and Management, Vilnius Gediminas Technical University, \\ Sauletekio al. 11, LT-10223 Vilnius, Lithuania \\ ${ }^{d}$ School of Housing, Building and Planning, Universiti Sains Malaysia, 11800 Minden, Penang, Malaysia
}

Received 17 Aug 2015; accepted 10 Nov 2015

\begin{abstract}
One of the major concerns in the construction industry is the sustainability of building projects. There are various trade-offs between functionality and design, which often lead to an issue of whether sustainably designed buildings would meet stakeholder requirements. This paper provides a novel integrated structure for assessing green buildings realistically based on stakeholders' fuzzy preferences. In particular, the paper uses the analytic network approach (ANP) to evaluate the correlation matrices in a quality function deployment (QFD) framework. A case study on green building index assessment in Malaysia illustrates the proposed integrated method. Sensitivity analysis validated the customerstakeholder agreement towards the design of the green building. Cluster analysis was also used to group design specifications prior to the analysis.
\end{abstract}

Keywords: MCDM, fuzzy ANP, QFD, green building assessment, performance evaluation.

\section{Introduction}

Construction buildings and their energy consuming activities have attracted a considerable attention from both practitioners and academics (Dixit et al. 2010). In particular, building construction consumes about 30 to 40 percent of the total energy in the UK, EU, US, Japan and Hong Kong, respectively (Juan et al. 2010). In the process, this contributes largely to environmental pollutions and greenhouse gasses, which remain core issues in climate change (Wang et al. 2005; Dixit et al. 2010). The environmental impact will continue rise as a result of rapid development of building activities catering to the continuing global population growth, as projected to be 9 billion in 2035 (Dixit et al. 2010). Therefore, the challenge faced by the building sector is to adapt towards rapid urbanization in an ecologically responsible manner (Du Plessis 2007).

Thus, environmentally sustainable construction (e.g. green building, ecological building or sustainable architecture) became important topics in assessing the entire life cycle, including the usage of raw materials to how recycling of wastes are developed. In short, sustainable construction can be defined as a responsible management of a healthy built environment based on resource efficient and ecological principles (Bourdeau 1999). Sustainable built environment includes green buildings and the positive impact on energy consumption, such as the productivity gains from employee as a result of improvements in an indoor environment, cost savings from the operations and maintenance (Ries et al. 2006). As a result, it is not surprising that the demand for green and resource-efficient practices in the architecture, engineering and construction (AEC) industries are on the rise.

In the assessment of green building performance (i.e. building impact) on the environment, various building rating systems (BRS) have been developed to assist the architecture and engineering professionals. The green rating system provides a comprehensive framework and guideline on how to measure and implement green building designs and their construction. Generally, different countries launch different environmental rating systems by emphasizing on the different aspects of building evaluation. For example, Building Research Establishment Environmental Assessment Method (BREEAM) was launched in UK in 1990 (Lee, Burnett 2008), Leadership in Energy and Environmental Design (LEED) in USA in

Corresponding author: Jonas Šaparauskas

E-mail: jonas.saparauskas@vgtu.lt 
1998 (Šaparauskas 2003; Kwok, Rajkovich 2010), Green Star in Australia in 2003 (Lockwood 2006), Comprehensive Assessment System for Built Environment Efficiency (CASBEE) in Japan in 2001 (Murakami et al. 2011), Green Rating for Integrated Habitat Assessment (GRIHA) in India in 2008 (Balachandra et al. 2010), Green Mark in Singapore in 2005 (Hwang, Tan 2012) and Green Building Index in Malaysia in 2009 (Darus et al. 2009).

The performance of the building is influenced by the design goals (NREL 2006). Menassa and Baer (2014) indicated that the initial phase of the construction process (i.e. design planning), typically driven by the 4 E's concepts (everybody, engaging, everything, early a process discovery design) are essential in design planning. Joining both the customer requirements and stakeholder's production demands are important inputs in the very beginning of the construction process. One has to consider the methodology and manner of capturing all this information accurately. A technique such as quality function deployment (QFD) can be used to evaluate both customer and company perspectives in the product design through a structured framework (Liu, Wang 2010). QFD aids teamwork assessment which covers multiple criteria and interactive relationships among stakeholders and potential owners. This is in line with what decision makers need in making building design and construction decisions, which is a formalized analytical framework.

In addition, since the green building assessment tool requires a multi-dimensional assessment (Ali, Al Nsairat 2009; Kabak et al. 2014), the field of multi-criteria decision making (MADM) readily provides this means of capturing the judgment of decision makers, and subsequently weight, rank, select and optimize evaluation parameters in construction activities. MADM is employed to aid the decision maker in solving complicated problems, especially involving the evaluation of multiple stakeholders, multi-criteria or at least partially conflicting criteria, in the sense that factors affecting the decisions are often intertwined. In practical decision making situations, there may be a wide range of conflicting criteria and alternatives to be evaluated. Determining the priority importance of the criteria as well as selecting the best alternative within the set of available alternatives are always difficult for the decision maker. In the case of interrelated factors, a MADM technique, which is the Ana- lytic Network Process (ANP) proposed by Saaty (1996) is particularly useful in handling performance evaluation exercises (Wong et al. 2014).

However, in the real world, there are many cases where it is not possible to obtain precisely defined data (Ignatius et al. 2010, 2012; Yeap et al. 2014). Therefore, fuzzy set theory introduced by Zadeh (1975) was used to handle the subjectivity in decision inputs due to incomplete, ambiguous, non-obtainable or unquantifiable information (Lin, Wu 2008; Wu, Lee 2007). In this study, an integrated method of QFD and ANP with fuzzy set theory is proposed to assess the green building performance in Malaysia. Fuzzy analytic network process (FANP) is used to evaluate the independent and dependent relationships of the criteria in the QFD technique.

The rest of the paper is organized as follows. Section 1 describes the green building index (GBI) in Malaysia. Section 2 presents the literature review. Section 3 covers the methodology of QFD and Fuzzy ANP. Section 4 applies the integrated method on a case study. Section 5 discusses the findings with sensitivity analysis. At the end conclusions are presented.

\section{Green building index in Malaysia}

Early in 2000, the Malaysian government had embarked on a journey to create awareness for environmentally sustainable building. For instance, all government offices were directed to reduce the energy consumption by 10 percent (Chua, Oh 2011). Malaysians were urged not to sacrifice biodiversity in favour of economic development (Chin 2005). Despite all the efforts, prior to 2009, Malaysia did not have its own building rating system.

In May 2009, the first and only non-governmental driven rating system, known as the green building index (GBI) was launched by the Malaysian Institute of Architects (PAM) and the Association of Consulting Engineers Malaysia (ACEM) to provide a comprehensive framework for green building assessment. This subsequently enabled the green grading for Malaysian buildings. Based on the survey of numerous green building rating systems as shown in Table 1 (GBI 2009), six criteria (energy efficiency (EE), indoor environment quality (IEQ), sustainable site planning and management (SSPM), materials and resources (MR), water efficiency (WE) and innovation (IN)) were selected for evaluating the sustainability

Table 1. Green building assessment criteria

\begin{tabular}{ll}
\hline \multicolumn{1}{c}{ Rating system } & \multicolumn{1}{c}{ Assessment criteria } \\
\hline BREEAM, UK (1990) & $\begin{array}{l}\text { Management, health and well-being, energy, transport, water, materials, waste, land use and } \\
\text { ecology } \\
\text { LEED, USA (1998) }\end{array}$ \\
$\begin{array}{l}\text { Sustainable site, water efficiency, energy and atmosphere, materials and resources, indoor } \\
\text { environmental quality, innovation and design/construction process }\end{array}$ \\
Green Star, Australia (2003) & $\begin{array}{l}\text { Management, transport, land use and ecology, emissions, energy, materials, indoor } \\
\text { environmental quality, and innovation }\end{array}$ \\
Green Mark, Singapore (2005) & $\begin{array}{l}\text { Energy efficiency, water efficiency, environmental protection, indoor environment quality, } \\
\text { other green features and innovation } \\
\text { Energy efficiency (EE), indoor environment quality (IEQ), sustainable site planning and mana- } \\
\text { gement (SSPM), materials and resources (MR), water efficiency (WE), and innovation (IN) }\end{array}$ \\
&
\end{tabular}


Table 2. Definition of criteria

\begin{tabular}{|c|c|}
\hline Criterion & Definition \\
\hline $\mathrm{EE}$ & Increase the efficiency of energy consumption through building orientation, heat, lighting and best practices adoption \\
\hline IEQ & $\begin{array}{l}\text { Achieve the performance in air quality, acoustics, visual and thermal comfort in indoor environments by using low } \\
\text { volatile organic compound materials, quality air filtration and the controlling the air temperature, movement and } \\
\text { humidity }\end{array}$ \\
\hline SSPM & $\begin{array}{l}\text { Select the strategic sites with planned access to public transportation, community services, open spaces and } \\
\text { landscaping, while avoiding and conserving environmentally sensitive areas. Conduct proper construction } \\
\text { management, storm water management and reducing the strain on existing infrastructure capacity }\end{array}$ \\
\hline MR & Utilize environmentally friendly materials and implement the appropriate construction waste management \\
\hline WE & Use of recycling water, harvesting of rainwater and water-saving fittings \\
\hline IN & Use of other innovative designs and initiatives that ensure each of the GBI's objectives is achievable \\
\hline
\end{tabular}

of Malaysian buildings. These final 6 criteria were based on Malaysia's tropical climate, environmental and developmental context, and its tradition and culture. Table 2 presents the definitions of the six criteria used in the GBI.

Green Building Index (GBI) is developed specifically to: 1) establish the green building through a common language and standard of measurement, 2) promote the green building designs compatible to its surrounding, 3 ) create a sustainable built environment for improving the efficiency of the use of resources, workplace productivity and operational savings, 4) recognize and reward environmental leadership, and 5) upgrade existing buildings and ensure new buildings are well run, responsible and committed to the future.

To encourage the construction of green buildings, various initiatives were taken by the government of Malaysia, including an income tax exemption for building owners and stamp duty exemption on instruments of transfer of ownership passed under the Malaysian Budget 2010. Furthermore, under the Tenth Malaysia Plan (20112015), all new government buildings will be designed to meet the green standards.

There are currently 2 types of GBI rating tools in Malaysia, namely GBI for residential and GBI for nonresidential buildings, which can be further segregated into the rating tools such as residential new construction (RNC), non-residential new construction (NRNC), nonresidential existing building (NREB), industrial new construction (INC), industrial existing construction (IEC), NRNC: data center, NREB: data center, NRNC: retail, NREB: retail and township. To guide the building and construction sector in different types of sustainable constructions, Table 3 shows the different types of GBI rating tools with different scores. For instance, RNC and township rating tools pay more attention on the criterion of SSPM, whereas the rest of the rating tools emphasised more on the performance of EE.

At the end of the evaluation process, the certification level of the buildings is determined based on the total achieved points earned by each of the six criteria. A total score of 50 to 65 is required to achieve a certified rating of GBI, whereas the accumulated points of 66-75 points, $76-85$ and 86 points above will be awarded a sil- ver, gold and platinum level, respectively. However, the awarded GBI rating is only valid for three years and thus the re-evaluation of the building is needed to maintain the GBI rating.

Table 3. GBI rating systems

\begin{tabular}{lcccccc}
\hline \multicolumn{1}{c}{ GBI rating tool } & \multicolumn{7}{c}{ Criteria } \\
\hline & EE & IEQ & SSPM & MR & WE & IN \\
RNC & 23 & 12 & 33 & 12 & 12 & 8 \\
NRNC & 35 & 21 & 16 & 11 & 10 & 7 \\
NREB & 38 & 21 & 10 & 9 & 12 & 10 \\
INC & 33 & 22 & 18 & 10 & 10 & 7 \\
IEB & 38 & 22 & 10 & 8 & 12 & 10 \\
NRNC: Data Centre & 35 & 21 & 16 & 11 & 10 & 7 \\
NREB: Data Centre & 38 & 21 & 10 & 9 & 12 & 10 \\
NRNC: Retail & 35 & 21 & 16 & 11 & 10 & 7 \\
NREB: Retail & 38 & 21 & 10 & 9 & 12 & 10 \\
Township & 20 & 15 & 26 & 14 & 15 & 10 \\
\hline
\end{tabular}

\section{Literature review}

QFD was first conceptualized in the late 1960s by Dr Yoji Akao (Akao, Mazur 2003). QFD is a customer-driven quality management system that transforms customer needs into appropriate company requirements at each stage of product development and production, for the purposes of satisfying customer requirements. A successful QFD application brings the advantages of minimizing start-up cost, promoting group decision making (GDM), shorter design cycles and provision of documentation (Chan, Wu 2002; Büyüközkan, Cifci 2012).

Product development, quality management and customer needs analysis are the initial motivation behind the application of QFD. Later, QFD's function expanded to the area of design, planning, engineering timing, decision-making and costing (Chan, Wu 2002). Through these fields, QFD has been widely applied in various industries of manufacturing, transportation and communication, education and research, electronics and electrical utilities, software systems and services (Chan, Wu 2002). Interested readers can refer to more recent works that com- 
bined QFD and fuzzy multi-criteria decision making (see Behzadian et al. 2013; Motlagh et al. 2015).

In this study, a modified method of advance QFD from Liu and Wang (2010) is adapted. To effectively capture both the dependent and interdependent relationships of the criteria in the correlation matrices based on the subjective judgments of the decision makers, QFD is integrated with fuzzy analytic network process (FANP). In the fuzzy set concept, linguistic variables (words or sentences in natural or artificial language) are used to allow humans to deal with the difficulty of expressing opinions in overtly complex or hard to define problems (Zadeh 1975). In practice, mathematical terms such as fuzzy numbers are used to represent the decision maker's preferences in linguistic terms. On the other hand, FANP is an extension of the AHP approach, which was introduced by Saaty (1996) to eliminate the assumption of independence between the criteria or alternatives, so that accurate predictions or decisions can be made.

\section{A proposed fuzzy ANP-QFD method in green building evaluation}

In contrast to previous studies in building evaluation context, we are concerned about the integration between customer's perspective and company's perspectives in the product planning phase (also known as the house of quality, HoQ) of QFD. HoQ describes the initial process underlying QFD. For example, QFD from the customer perspective refers to the transition from customer requirements (CRs), "what the customer wants", to a list of design specifications (DSs), "how the customer requirements can be fulfilled". This matrix also evaluates the relationship between CRs and DSs, the importance weights of CRs and (DSs), company's target levels as well as customers' needs from the sales perspective. Figure 1 provides the QFD framework and the variables that we will compute by our proposed Fuzzy ANP method in the latter stages. Figure 2 shows the flowchart of our proposed QFD decision making process.
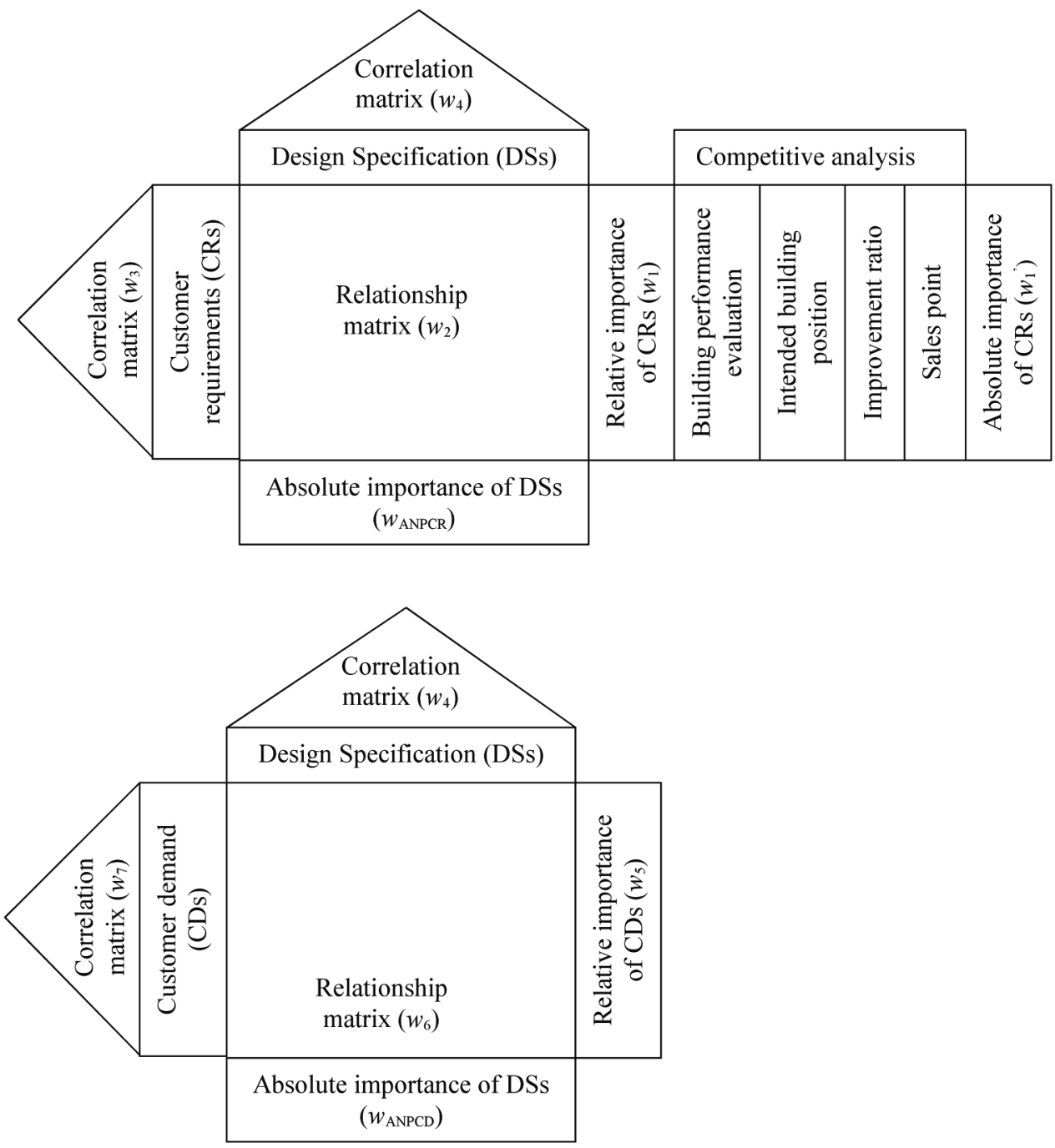

Fig. 1. QFD framework of the hybrid QFD- FANP method 


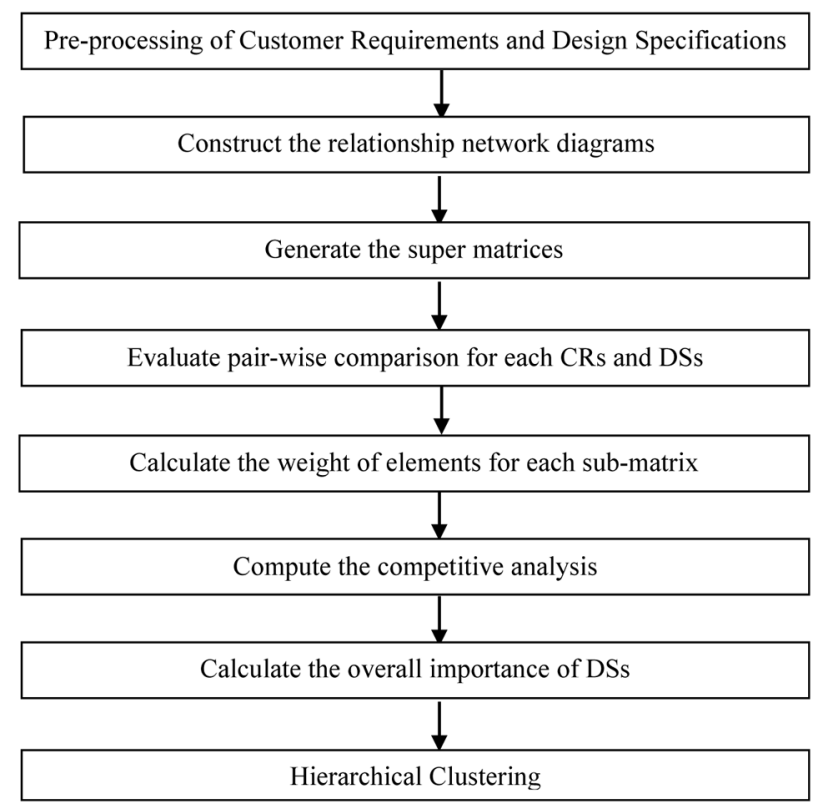

Fig. 2. Flow chart of the proposed fuzzy ANP-QFD method with hierarchical clustering

The steps of the modified fuzzy ANP- QFD framework are as follows.

Step 1: Establish the product development team.

Step 2: Pre-processing of Customer Requirements and Design Specifications.

The process begins with generating a proposed set of customer requirements (CRs), $C R=\left\{c r_{1}, c r_{2}, \ldots, c r_{n}\right\}$ and Design Specifications (DSs), $D S=\left\{d s_{1}, d s_{2}, \ldots, d s_{n}\right\}$ by the developer team. At the same time, developer's management group provides a proposed set of company demands (CDs), $C D=\left\{c d_{1}, c d_{2}, \ldots, c d_{n}\right\}$ for the evaluation.

Step 3: Construct the relationship network diagrams.

The process continues by establishing the network diagrams of the QFD charts. Figure 1(a) contains an extra item: the competitive analysis/subjective benchmarking as compared to the conventional QFD. The absolute importance of CRs $\left(w_{i}^{\prime}\right)$ in Figure 1(a) is obtained by incorporating the relative importance of CRs $\left(w_{i}\right)$ and the competitive analysis. The network diagram of QFD chart in Figure 1(a) is illustrated in Figure 3(a). Similarly, the network diagram of Figure 1(b) can be depicted in Figure 3(b).
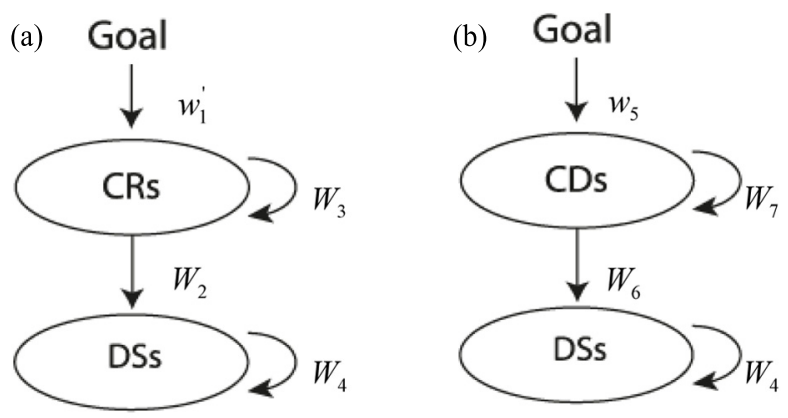

Fig. 3. Network diagrams for the proposed QFD framework
Step 4: Generate the super-matrices. The next step is to translate the established network diagrams in Figure 3 into their corresponding super-matrices as follows:

$$
\begin{gathered}
G \\
W_{A}= \\
\operatorname{Goal}(G) \\
C R s \\
D S s
\end{gathered}\left[\begin{array}{ccc}
0 & 0 & 0 \\
w_{1}^{\prime} & W_{3} & 0 \\
0 & W_{2} & W_{4}
\end{array}\right],
$$

where: $w_{1}^{\prime}$ is a vector that represents the absolute importance of CRs, $W_{2}$ is a matrix that indicates the impact level of CRs on each of the DSs, $W_{3}$ and $W_{4}$ are the matrices that indicate the inner dependence of CRs and DSs respectively.

The matrix in Eqn (2) corresponds to Figure 3(b):

$$
\begin{aligned}
& G \text { CDs DSs } \\
& W_{B}=\underset{C D s}{\operatorname{Coal}(G)}\left[\begin{array}{ccc}
0 & 0 & 0 \\
w_{5} & W_{7} & 0 \\
0 & W_{6} & W_{4}
\end{array}\right],
\end{aligned}
$$

where: $w_{5}$ is the vector that represents the relative importance of CDs, $W_{6}$ indicate the impact level of CDs on each DSs, $W_{4}$ and $W_{7}$ are the vectors that indicate the inner dependence of CDs.

Step 5: Obtain the importance weights for each CRs, and DSs.

Step 5.1: Compute the competitive analysis.

The sub matrix $w_{1}^{\prime}$ in Figure 1(a) denotes the absolute importance of CRs that can be computed by combining the relative importance of CRs $\left(w_{1}\right)$ and competitive analysis. From the competitive analysis, the information of current building performance evaluation, the intended building rating position for CRs, improvement ratio and the sales point determination are needed for absolute importance of CRs evaluation. The normalized absolute weight of CRs can be obtained using Eqn (3):

$$
w_{1}^{\prime}=\frac{\text { absolute weight }}{\text { Mabsolute weight }}
$$

Normalized absolute weight $\left(w_{1}^{\prime}\right)=w_{1}(.) w_{I R}(.) w_{S P} ;(3)$

$$
w_{I R}=w_{M P} \cdot w_{C P},
$$

where: $w_{I R}$ - the vector formed by the improvement ratio of CRs; $w_{S P}$ - the vector formed by the sales points; $w_{M P}$ - the vector formed by the intended market position of CRs; $w_{C P}$ - the vector formed by the current performance of CRs.

Step 5.2: Conduct pairwise comparisons for the elements in the whole system.

Other than the weights of $w_{1}^{\prime}$, the QFD's team conducted the pairwise comparisons of the relative importance between each of the sets of criteria in the matrices of $w_{2}-w_{7}$ using the fuzzy scales as shown in Table 4, thus leading to six fuzzy pair-wise comparison matrices. 
Table 4. Linguistic variables and correspond TFNs

\begin{tabular}{lcc}
\hline \multicolumn{1}{c}{ Linguistic Variables } & $\begin{array}{c}\text { Correspond } \\
\text { Triangular } \\
\text { Fuzzy Numbers }\end{array}$ & $\begin{array}{c}\text { Reciprocal } \\
\text { Fuzzy } \\
\text { Numbers }\end{array}$ \\
\hline Equally important & $(1,1,1)$ & $(1,1,1)$ \\
Weakly more important & $(1,3,5)$ & $(1 / 5,1 / 3,1)$ \\
Strongly more important & $(3,5,7)$ & $(1 / 7,1 / 5,1 / 3)$ \\
Absolutely more important & $(5,7,9)$ & $(1 / 9,1 / 7,1 / 5)$ \\
\hline
\end{tabular}

Assume the pair-wise comparison matrix is denoted by $E=\left[\tilde{e}_{i j}\right]_{m x m}$, where $\tilde{e}_{i j}=\left(e_{i j}^{l}, e_{i j}^{h}, e_{i j}^{u}\right)$ expresses the relative importance of element $i$ as compared to element $j$ in fuzzy linguistic terms (see Table 4). Note that $\tilde{e}_{i j}=\frac{1}{\tilde{e}_{j i}}$.

Step 5.3: Compute the importance weights of each criterion.

The fuzzy weight of elements for each sub matrix are derived using the $\lambda_{\max }$ method proposed by Csutora and Buckley (2001). The steps of Csutora and Buckley's Lambda-Max technique used in FANP are summarized as follows.

Let $\alpha-c u t=1$ to obtain the matrix $E_{h}=\left[e_{i j}^{h}\right]_{m \times m}$ which is formed by the entities with the highest membership value in matrix $\boldsymbol{E}$. Then traditional AHP is applied to calculate its weight vector:

$$
w_{h}=\left[w_{i}^{u}\right]_{m \times m}, i=1,2, \ldots, m .
$$

Let $\alpha-c u t=0$ to obtain the lower bound matrix $E_{l}=\left[e_{i j}^{l}\right]_{m \times m}$ and the upper bound matrix $E_{u}=\left[e_{i j}^{u}\right]_{m \times m}$ of matrix $\boldsymbol{E}$. Then traditional AHP is applied to calculate the corresponding weight vectors $w_{l}$ and $w_{u}$, respectively $w_{l}=\left[w_{i}^{l}\right], i=1,2, \ldots m$.

$$
w_{u}=\left[w_{i}^{u}\right], i=1,2, \ldots m .
$$

To ensure the accuracy of fuzzy weight, two constants, $s_{l}$ and $s_{u}$, are calculated as follows:

$$
\begin{aligned}
& s_{l}=\min \left\{\frac{w_{i}^{h}}{w_{i}^{l}} \mid 1 \leq i \leq m\right\} ; \\
& s_{u}=\max \left\{\frac{w_{i}^{h}}{w_{i}^{u}} \mid 1 \leq i \leq m\right\} .
\end{aligned}
$$

The lower bound $\left(r_{l}\right)$ and upper bound $\left(r_{u}\right)$ of the revised weight vector are defined as follows:

$$
\begin{gathered}
r_{l}=\left[r_{i}^{l}\right], r_{i}^{l}=s_{l} w_{i}^{l}, i=1,2, \ldots, m ; \\
r_{u}=\left[r_{i}^{u}\right], r_{i}^{u}=s_{u} w_{i}^{u}, i=1,2, \ldots, m .
\end{gathered}
$$

Aggregating vectors $r_{l}, w_{h}$ and $r_{u}$, the final weight vector is acquired as follows:

$$
f w=\left[\tilde{f} w_{i}\right]=\left[\left(r_{i}^{l}, w_{i}^{h}, r_{i}^{u}\right], i=1,2, \ldots, m,\right.
$$

where: $\tilde{f} w_{i}$ is the fuzzy weight of element $i$.

To obtain the crisp value of each criterion, the fuzzy weight of element such as $\left(r_{i}^{l}, w_{i}^{h}, r_{i}^{u}\right)$ is translated into crisp value by using centroid method as follows:

$$
\tilde{w}_{i j}=\left(r_{i}^{l}, w_{i}^{h}, r_{i}^{u}\right) / 3 .
$$

To ensure the assessed values in the pair-wise comparison matrix $\boldsymbol{E}$ is acceptable, consistency check is performed and shown as follows:

$$
\begin{gathered}
C I=\frac{\lambda_{\operatorname{Max}}-n}{n-1} ; \\
C R=\frac{C I}{R I},
\end{gathered}
$$

where: $\lambda_{\text {Max }}$ is the largest eigenvalue of matrix $\boldsymbol{E}, \mathrm{CI}$ is the consistency index of matrix $\boldsymbol{E}, R I$ is the random index of matrix $\boldsymbol{E}$ and $C R$ is denoted as the consistency ratio of matrix $\boldsymbol{E}$.

The consistency ratio of the matrix, $C R<0.1$ indicates that the matrix $\boldsymbol{E}$ is considered reasonable and acceptable. Otherwise, the assessed values in matrix $\boldsymbol{E}$ should be revised or reassessed.

The final weight vector $f \boldsymbol{w}$ is obtained based on the evaluation of individual decision maker. If there are $n$ decision makers in the QFD team, the average weight of elements can be computed by:

$$
\tilde{f} w_{i}=\frac{1}{n} \sum_{j=1}^{n} \tilde{f} w_{i}^{j}, i=1,2, \ldots, m, j=1,2, \ldots n,
$$

where: $\tilde{f} w_{i}^{j}$ is the weight of element $i$ with regard to decision maker $j$.

Step 5.4: Calculate the overall importance of DSs.

In the traditional ANP approach, the super-matrix is raised to limiting powers in order to calculate the overall weight of the elements. Here, we adopt an alternative and efficient method, used in Karsak et al. (2003), Büyüközkan et al. (2007), Ertay et al. (2005), and Kahraman et al. (2006), to calculate the overall weight of the elements. Take the super-matrix $w_{a}$ as an example. The approach is first to calculate the interdependent importance of DSs, $w_{D S}$, as follows:

$$
w_{D S}=w_{4} \times w_{2}
$$

The interdependent importance of CRs, $w_{C R}$, is then calculated by:

$$
w_{C R}=w_{3} \times w_{1}^{\prime}
$$

Finally, the absolute importance of DSs, $w_{A N P}$, for $w_{a}$ is calculated by:

$$
w_{A N P C R}=w_{D S} \times w_{C R} \text {. }
$$


Since super-matrix $w_{A N P C D}$ is similar to super-matrix, $w_{A N P C R}$, the absolute importance of DSs, $w_{A N P C D}$, for the super-matrix $w_{b}$ can be derived in the same way:

$$
w_{A N P C D}=\left(w_{4} \times w_{6}\right) \times\left(w_{7} \times w_{5}\right) .
$$

Notice that the vectors $w_{A N P C R}$ and $w_{A N P C D}$ denote the importance of DSs from the customer's and company's perspectives, respectively. To combine both vectors into the final (aggregated) importance of DSs, both vectors are first normalized. Assuming $w_{A N C P R}=\left[\tilde{b}_{i}\right], i=1,2, \ldots, p$ the normalization formula is given as follows:

$$
\dot{w}_{A N C P R}=\left[\frac{\tilde{b}_{i}}{B}\right], B=\sum_{i} b_{i}, i=1,2, \ldots, p,
$$

where: $w_{A N P C R}$ is the normalized importance of DSs from customer's perspectives.

Similarly, the vector $w$ can be normalized as $w_{A N P C D}$ in the same way. The final importance of DSs, i.e. $w_{A N P}$ can be computed by:

$$
w_{A N P}=\beta \cdot w_{A N P C R}(+)(1-\beta) \cdot w_{A N P C D},
$$

where: $\beta$ is defined as a customer-importance index, $0 \leq \beta \leq 1$. The value of $\beta$ is assessed by the developer. When the value of $\beta$ becomes larger (smaller), customer's (company's) opinions are more important. Then, the weights, $w_{A N P C R}$ is ranked accordingly.

Step 6: Hierarchical Clustering.

Once the results from modified Fuzzy ANP-QFD method are obtained, the importance levels of DSs can be classified into few distinct groups. For example, developers can classify the importance level of DSs into three groups; low, moderate, and high. To achieve this objective, a clustering technique is needed. Among numerous clustering algorithms (eg. hierarchical clustering, c-means clustering, and $k$-means clustering), the hierarchical clustering may be the most attractive in practice since it shows a clear and useful dendogram graph. Basically the hierarchical clustering algorithm consists of two types, which is an agglomerative hierarchical clustering algorithm or AGNES (agglomerative nesting), and divisive hierarchical clustering algorithm or DIANA (divisive analysis). In this study, complete linkage method of the Agglomerative Hierarchical clustering algorithm is used in clustering the data by grouping the data one by one on the basis of the nearest distance measure of all the pairwise distances between the data points.

Complete-linkage clustering algorithm considers the distance between two clusters to be equal to the longest distance from any member of one cluster to any member of the other cluster. The algorithm procedures for grouping $N$-object are as follows:

1) Start with $N$ clusters, each containing a sing entity and an $N x N$ symmetric matrix of distances (or similarities) $D=\left\{d_{i k}\right\}$;
2) Search the distance matrix for the nearest (most similar) pair of clusters. Let the distance between "most similar" clusters $U$ and $V$ be $d_{U V}$;

3) Merge clusters $U$ and $V$. Label the newly formed cluster $(U V)$. Update the entries in the distance matrix by deleting the rows and columns corresponding to clusters $U$ and $V$;

4) Adding a row and a column giving the distances between cluster $(U V)$ and the remaining clusters;

5) Repeat Steps 2 and 3 a total of $N-1$ times. Record the identity of clusters that are merged and the levels (distance or similarities) at which the mergers take place.

\section{Case study}

To illustrate the proposed integrated model of QFD and Fuzzy ANP, a case study of construction company $X$ that focuses on the green building construction with silver GBI rating in Malaysia is presented. Applying the steps in Section 3, we have:

Step 1: Establish the product development team.

A QFD team, which consisted of 5 experts (e.g. developer) from private construction companies and professional bodies was formed.

Step 2: Identify customer requirements, design specifications and company demands.

Based on the broad knowledge and experience in green building development, the customer (e.g. applicant of GBI certification) requirements (CRs) were determined by interviewing the applicant interested in "green building". In this study, the customer requirements are based on the criteria of the green building index. Having understood the customer needs, 7 design specifications (DSs) were determined by the QFD team to measure the customer needs. The established CRs, CDs, and DSs are

\begin{tabular}{|c|c|c|}
\hline $\begin{array}{l}\text { Customer Requirements } \\
\text { (CRs) }\end{array}$ & $\begin{array}{c}\text { Design } \\
\text { Specifications } \\
\text { (DSs) }\end{array}$ & $\begin{array}{l}\text { Company } \\
\text { Demands } \\
\text { (CDs) }\end{array}$ \\
\hline $\begin{array}{l}\text { Energy efficiency }\left(\mathrm{CR}_{1}\right) \\
\text { Indoor environmental } \\
\text { quality }\left(\mathrm{CR}_{2}\right) \\
\text { Sustainable site planning } \\
\& \text { management }\left(\mathrm{CR}_{3}\right) \\
\text { Material \& resources } \\
\left(\mathrm{CR}_{4}\right) \\
\text { Water efficiency }\left(\mathrm{CR}_{5}\right) \\
\text { Innovation }\left(\mathrm{CR}_{6}\right)\end{array}$ & $\begin{array}{l}\text { Landscaping } \\
\left(\mathrm{DS}_{1}\right) \\
\text { Shape of building } \\
\left(\mathrm{DS}_{2}\right) \\
\text { Size of building } \\
\left(\mathrm{DS}_{3}\right) \\
\text { Lighting }\left(\mathrm{DS}_{4}\right) \\
\text { Structure of } \\
\text { building }\left(\mathrm{DS}_{5}\right) \\
\text { Space }\left(\mathrm{DS}_{6}\right) \\
\text { Location } \\
\text { environment } \\
\left(\mathrm{DS}_{7}\right)\end{array}$ & $\begin{array}{l}\text { Construction } \\
\text { cost (CD1) } \\
\text { Construction } \\
\text { duration } \\
\text { (CD2) } \\
\text { Strength of } \\
\text { Building } \\
\text { (CD3) }\end{array}$ \\
\hline
\end{tabular}
summarized in Table 5.

Table 5. Establish CRs, DSs, and CDs

Step 3: Determine the importance degree of CRs: Calculation of $w_{1}^{\prime}$.

Assuming that there is no dependence among the $\mathrm{CRs}$, the relative importance of CRs $\left(w_{1}\right)$ is determined 
Table 6. Evaluation results for the competitive analysis

\begin{tabular}{cccccccccc}
\hline CRs & $\begin{array}{c}\text { Maximum } \\
\text { score }\end{array}$ & $w_{1}$ & $\begin{array}{c}\text { Current building } \\
\text { performance score } \\
\left(w_{c p}\right)\end{array}$ & $\begin{array}{c}\text { Intended } \\
\text { building } \\
\text { position }\end{array}$ & $\begin{array}{c}\text { Target } \\
\text { Score } \\
\left(w_{m p}\right)\end{array}$ & $\begin{array}{c}\text { Improvement } \\
\text { ratio } \\
\left(w_{i r}\right)\end{array}$ & $\begin{array}{c}\text { Sales point } \\
\left(w_{s p}\right)\end{array}$ & $\begin{array}{c}\text { Absolute } \\
\text { weight }\end{array}$ & $w_{1}^{\prime}$ \\
\hline $\mathrm{CR}_{1}$ & 23 & 0.23 & 17 & 15.18 & 17 & 1 & 1.8 & 0.414 & 0.2661 \\
$\mathrm{CR}_{2}$ & 12 & 0.12 & 3 & 7.92 & 8 & 2.67 & 1 & 0.32 & 0.2057 \\
$\mathrm{CR}_{3}$ & 37 & 0.37 & 27 & 24.42 & 27 & 1.08 & 1.2 & 0.444 & 0.2854 \\
$\mathrm{CR}_{4}$ & 10 & 0.10 & 6 & 6.6 & 7 & 1.17 & 1.3 & 0.1517 & 0.0975 \\
$\mathrm{CR}_{5}$ & 12 & 0.12 & 6 & 7.92 & 8 & 1.33 & 1 & 0.16 & 0.1028 \\
$\mathrm{CR}_{6}$ & 6 & 0.06 & 4 & 3.96 & 4 & 1 & 1.1 & 0.066 & 0.0424 \\
Total & 100 & 1.00 & 61 & 66 & 71 & & & 1.591 & \\
\hline
\end{tabular}

Table 7. Fuzzy comparison matrix for company demands (CDs), $w_{5}$

\begin{tabular}{rlrlrrrrrrrr}
\hline$w_{5}$ & \multicolumn{1}{c}{$\mathrm{CD}_{1}$} & $\mathrm{CD}_{2}$ & \multicolumn{1}{c}{$\mathrm{CD}_{3}$} & $w_{h}$ & $w_{l}$ & $w_{u}$ & $r_{l}$ & $r_{u}$ & Fuzzy Weight & $w_{5}$ \\
\hline $\mathrm{CD}_{1}$ & $(1,1,1)$ & $(5,7,9)$ & $(1,3,5)$ & 0.669 & 0.644 & 0.590 & 0.535 & 0.669 & $(0.535,0.669,0.669)$ & 0.6241 \\
$\mathrm{CD}_{2}$ & $(1 / 9,1 / 7,1 / 5)$ & $(1,1,1)$ & $(1 / 5,1 / 3,1)$ & 0.088 & 0.106 & 0.100 & 0.088 & 0.114 & $(0.088,0.088,0.114)$ & 0.0967 \\
$\mathrm{CD}_{3}$ & $(1 / 5,1 / 3,1)$ & $(1,3,5)$ & $(1,1,1)$ & 0.243 & 0.250 & 0.310 & 0.208 & 0.352 & $(0.208,0.243,0.352)$ & 0.2675 \\
\hline
\end{tabular}

Note: $C I=0.004, C R=0.007$.

based on GBI rating, which is shown in Table 6. Since the GBI rating for building is targeted as silver, the current performance of the company's building (or based on the historical data) on meeting the customer needs is compared with the standard GBI rating. Thus, the information of the current building performance score, intended building position (e.g. silver rating), target score, improvement ratio and sales point are needed to generate the absolute importance of CRs $\left(w_{1}^{\prime}\right)$. Notice that to qualify for a silver rating for the green building, at least 66 out of 100 score points (or 0.66 ) for building evaluation needs to be achieved.

For example, the intended building performance, target score, improvement ratio, sales point and absolute weights for $\mathrm{CR}_{1}$ in Table 6 can be determined as follows (refer step 5.1 in Section 3):

Current building performance score $=17$ (determined by the QFD team);

Intended building position $\left(\mathrm{CR}_{1}\right)=23$ points* $0.66=15.18$ points.

Compare with current building performance score and intended building position, the maximum score in integer will be chosen. Thus, target score for $\mathrm{CR}_{1}=17$.

Improvement ratio of $\mathrm{CR}_{1}=$ Target score/present score $=17 / 17=1$.

Sales point for $\mathrm{CR}_{1}=1.8$ (determined by the QFD team);

Absolute weight for $\mathrm{CR}_{1}=0.23$ (1) (1.8) =0.414;

Normalized absolute weight of $\mathrm{CR}_{1}=0.414$ / $(0.414+0.32+0.444+0.1517+0.16+0.066)=0.2661$.

Step 4: Determining the importance weights for the matrices $W_{2}$ to $W_{7}$.
QFD team is required to conduct pair-wise comparisons for the matrices of $W_{2}$ to $W_{7}$ by using the fuzzy linguistic variable shown in Table 4. Given that the preference structure of company demands is in fuzzy linguistic terms, we present $w_{5}$ before dealing with the remaining weight matrices of $W_{2}, W_{3}, W_{4}, W_{6}$ and $W_{7}$. By referring to Step 5.3 in Section 3, the fuzzy weights and consistency index, consistency ratio and crisp weights for CDs are shown in Table 7.

Similarly, the relative weights of $W_{2}$ to $W_{7}$ can be derived from the corresponding fuzzy comparison matrix using the fuzzy ANP approach. The relative weight results are shown in Tables 8-12.

Table 8. Relative weights for $W_{2}$

\begin{tabular}{lrrrrrc}
\hline$W_{2}$ & $\mathrm{CR}_{1}$ & $\mathrm{CR}_{2}$ & $\mathrm{CR}_{3}$ & $\mathrm{CR}_{4}$ & $\mathrm{CR}_{5}$ & $\mathrm{CR}_{6}$ \\
\hline $\mathrm{DS}_{1}$ & 0.0305 & 0.2642 & 0.1548 & 0.0634 & 0.2642 & 0.0512 \\
$\mathrm{DS}_{2}$ & 0.2770 & 0.0481 & 0.3709 & 0.1146 & 0.0481 & 0.1626 \\
$\mathrm{DS}_{3}$ & 0.0523 & 0.1936 & 0.0713 & 0.2429 & 0.1936 & 0.2242 \\
$\mathrm{DS}_{4}$ & 0.2173 & 0.1187 & 0.1260 & 0.1059 & 0.1187 & 0.1871 \\
$\mathrm{DS}_{5}$ & 0.2037 & 0.0365 & 0.1579 & 0.3112 & 0.0365 & 0.3091 \\
$\mathrm{DS}_{6}$ & 0.1718 & 0.1087 & 0.0298 & 0.0936 & 0.1087 & 0.0338 \\
$\mathrm{DS}_{7}$ & 0.0391 & 0.2069 & 0.0745 & 0.0373 & 0.2069 & 0.0427 \\
\hline
\end{tabular}

Step 5: Determine the overall importance of CRs and CDs.

The absolute importance of DSs from customer perspective, $w_{A N P C R}$ is calculated by using Eqns (13)-(15). Similarly, the absolute importance of DSs from company perspective, $w_{A N P C D}$ can be derived using Eqn (16). 
Table 9. Relative weights for $W_{3}$

\begin{tabular}{rrrrrrr}
\hline$W_{3}$ & $\mathrm{CR}_{1}$ & $\mathrm{CR}_{2}$ & $\mathrm{CR}_{3}$ & $\mathrm{CR}_{4}$ & $\mathrm{CR}_{5}$ & $\mathrm{CR}_{6}$ \\
\hline $\mathrm{CR}_{1}$ & 0.2764 & 0.1268 & 0.0828 & 0.2977 & 0.0767 & 0.1260 \\
$\mathrm{CR}_{2}$ & 0.0827 & 0.0643 & 0.1019 & 0.0357 & 0.1309 & 0.0492 \\
$\mathrm{CR}_{3}$ & 0.4247 & 0.3784 & 0.2866 & 0.0903 & 0.2644 & 0.3556 \\
$\mathrm{CR}_{4}$ & 0.0775 & 0.1075 & 0.4064 & 0.1470 & 0.4151 & 0.1995 \\
$\mathrm{CR}_{5}$ & 0.0904 & 0.0484 & 0.0422 & 0.1352 & 0.0431 & 0.0405 \\
$\mathrm{CR}_{6}$ & 0.0418 & 0.2316 & 0.0390 & 0.2977 & 0.0392 & 0.1796 \\
\hline
\end{tabular}

Table 10. Relative weights for $W_{4}$

\begin{tabular}{lrrrrrrr}
\hline$W_{4}$ & $\mathrm{DS}_{1}$ & $\mathrm{DS}_{2}$ & $\mathrm{DS}_{3}$ & $\mathrm{DS}_{4}$ & $\mathrm{DS}_{5}$ & $\mathrm{DS}_{6}$ & $\mathrm{DS}_{7}$ \\
\hline $\mathrm{DS}_{1}$ & 0.1516 & 0.0305 & 0.1470 & 0.1003 & 0.1231 & 0.1592 & 0.1404 \\
$\mathrm{DS}_{2}$ & 0.0339 & 0.2769 & 0.0326 & 0.1745 & 0.1094 & 0.0346 & 0.0462 \\
$\mathrm{DS}_{3}$ & 0.3414 & 0.0522 & 0.3154 & 0.3120 & 0.3403 & 0.3601 & 0.3121 \\
$\mathrm{DS}_{4}$ & 0.2335 & 0.2173 & 0.2504 & 0.1924 & 0.1826 & 0.1841 & 0.2455 \\
$\mathrm{DS}_{5}$ & 0.0485 & 0.2036 & 0.0358 & 0.0734 & 0.0413 & 0.0474 & 0.0425 \\
$\mathrm{DS}_{6}$ & 0.0510 & 0.1717 & 0.0532 & 0.0476 & 0.0415 & 0.0521 & 0.0525 \\
$\mathrm{DS}_{7}$ & 0.1379 & 0.039 & 0.1324 & 0.0552 & 0.1550 & 0.1560 & 0.1400 \\
\hline
\end{tabular}

Table 11. Relative weights for $W_{6}$

\begin{tabular}{lccc}
\hline \multicolumn{1}{c}{$W_{6}$} & $\mathrm{CD}_{1}$ & $\mathrm{CD}_{2}$ & $\mathrm{CD}_{3}$ \\
\hline $\mathrm{DS}_{1}$ & 0.0326 & 0.0550 & 0.2950 \\
$\mathrm{DS}_{2}$ & 0.3166 & 0.1550 & 0.0788 \\
$\mathrm{DS}_{3}$ & 0.0534 & 0.2286 & 0.1597 \\
$\mathrm{DS}_{4}$ & 0.2076 & 0.1920 & 0.1155 \\
$\mathrm{DS}_{5}$ & 0.1693 & 0.2880 & 0.0325 \\
$\mathrm{DS}_{6}$ & 0.1785 & 0.0337 & 0.1041 \\
$\mathrm{DS}_{7}$ & 0.0375 & 0.0564 & 0.2084 \\
\hline
\end{tabular}

First, the interdependence importance of DSs, $w_{D S}$ is calculated as follows:

$$
\begin{aligned}
& w_{D S}=w_{4} \times w_{2}= \\
& {\left[\begin{array}{ccccccc}
0.1005 & 0.1328 & 0.0926 & 0.1179 & 0.1328 & 0.1139 \\
0.1474 & 0.0667 & 0.1541 & 0.0993 & 0.0667 & 0.1237 \\
0.2526 & 0.3070 & 0.2218 & 0.2886 & 0.2070 & 0.2858 \\
0.2007 & 0.221 & 0.2115 & 0.2042 & 0.221 & 0.2127 \\
0.094 & 0.0537 & 0.106 & 0.0618 & 0.537 & 0.0736 \\
0.0817 & 0.0558 & 0.0935 & 0.0607 & 0.0558 & 0.0682 \\
0.0978 & 0.1221 & 0.0918 & 0.1193 & 0.1221 & 0.1126
\end{array}\right] .}
\end{aligned}
$$

Table 12. Relative weights for $W_{7}$

\begin{tabular}{lccc}
\hline \multicolumn{1}{c}{$W_{7}$} & $\mathrm{CD}_{1}$ & $\mathrm{CD}_{2}$ & $\mathrm{CD}_{3}$ \\
\hline $\mathrm{CD}_{1}$ & 0.4524 & 0.0921 & 0.4865 \\
$\mathrm{CD}_{2}$ & 0.4524 & 0.7038 & 0.0846 \\
$\mathrm{CD}_{3}$ & 0.1009 & 0.1922 & 0.4318 \\
\hline
\end{tabular}

Then, the interdependence importance of CRs, $w_{C R}$ is calculated by:

$$
w_{C R}=w_{3} \times w_{1}=
$$

Energy efficiency $\left(C R_{1}\right)$

Indoor environmental quality $\left(C R_{2}\right)$

Sustainable site planning and management $\left(C R_{3}\right)$

Material and resources $\left(C R_{4}\right)$

Water efficiency $\left(C R_{5}\right)$

Innovation $\left(\mathrm{CR}_{6}\right)$

$$
\left(\begin{array}{l}
0.1656 \\
0.0834 \\
0.3238 \\
0.2242 \\
0.0654 \\
0.1106
\end{array}\right) .
$$


Table 13. Final importance of DSs

\begin{tabular}{lcccccc}
\hline & $\begin{array}{c}\text { Normalized } \\
w_{A N P C R}\end{array}$ & Ranking & $\begin{array}{c}\text { Normalized } \\
w_{A N P C D}\end{array}$ & Ranking & $w_{A N P}$ & Ranking \\
\hline $\mathrm{DS}_{1}$ & 0.1120 & 4 & 0.1130 & 4 & 0.1123 & 4 \\
$\mathrm{DS}_{2}$ & 0.1275 & 3 & 0.1277 & 3 & 0.1275 & 3 \\
$\mathrm{DS}_{3}$ & 0.2716 & 1 & 0.2767 & 1 & 0.2732 & 1 \\
$\mathrm{DS}_{4}$ & 0.2166 & 2 & 0.2149 & 2 & 0.2161 & 2 \\
$\mathrm{DS}_{5}$ & 0.0847 & 6 & 0.0832 & 6 & 0.0843 & 6 \\
$\mathrm{DS}_{6}$ & 0.0777 & 7 & 0.0757 & 7 & 0.0771 & 7 \\
$\mathrm{DS}_{7}$ & 0.1098 & 5 & 0.1087 & 5 & 0.1095 & 5 \\
\hline
\end{tabular}

Finally, the absolute importance of DSs, $w_{A N P C R}$ is calculated by:

$$
w_{A N P C R}=w_{D S} \times w_{C R}=\left(\begin{array}{c}
0.1054 \\
0.1201 \\
0.2556 \\
0.2039 \\
0.0799 \\
0.0732 \\
0.1033
\end{array}\right) \text {. }
$$

Similarly, the absolute importance of CDs, $w_{A N P C D}$ is derived as follows:

$$
w_{A N P C D}=\left(w_{4} \times w_{6}\right) \times\left(w_{7} \times w_{5}\right)=\left(\begin{array}{c}
0.1102 \\
0.1244 \\
0.2697 \\
0.2095 \\
0.0811 \\
0.0738 \\
0.1059
\end{array}\right) \text {. }
$$

In order to aggregate and use the final importance of DSs in the next phase of QFD, the absolute importance $w_{A N P C R}$ and $w_{A N P C D}$ are normalized using Eqn (17). The normalized matrices are shown in Table 13. From the normalized $w_{A N P C R}$ and $w_{A N P C D}$, the final importance of DSs $w_{A N P}$ is calculated using Eqn (18) and the results are shown in Table 13.

Step 6: Clustering.

Lastly, the final importance of DSs, $w_{A N P}$ is classified into few groups using hierarchy clustering. Figure 4 shows the dendrogram of hierarchy clustering for final importance of DSs. The final importance of DS is basically classified into 3 classes as shown in Table 14 .

Table 14. Clustering result for vectors $w_{A N P}$

\begin{tabular}{ccc}
\hline Low & Moderate & High \\
\hline$\left\{\mathrm{DS}_{1}, \mathrm{DS}_{2}, \mathrm{DS}_{5}, \mathrm{DS}_{6}, \mathrm{DS}_{7}\right\}$ & $\left\{\mathrm{DS}_{4}\right\}$ & $\left\{\mathrm{DS}_{3}\right\}$ \\
\hline
\end{tabular}

\section{Discussion and sensitivity analysis}

By introducing the competitive analysis in QFD (refer Table 6), additional information can be obtained. First, as observed in the second column of Table 6 , the order ranking of the relative importance of $\mathrm{CRs}$ is $\mathrm{CR}_{3}>\mathrm{CR}_{1}>$ $\mathrm{CR}_{5}>\mathrm{CR}_{2}>\mathrm{CR}_{4}>\mathrm{CR}_{6}$. Note that $\mathrm{CR}_{3}$ has the highest relative importance weight from the customer perspective indicating that it is prioritised highest by the government and public authorities in achieving green residential buildings, while $\mathrm{CR}_{6}$ is the least important in the current case study. The building performance score $\left(4^{\text {th }}\right.$ column Table 6), indicates that only $\mathrm{CR}_{1}$ and $\mathrm{CR}_{6}$ meet the target score, while the other CRs are unsatisfactory in that regard, which is essential in highlighting the company's strengths and constraints in achieving the silver GBI award. Also note that among the six customer requirements, $\mathrm{CR}_{1}$ has the highest sales point value and thus is chosen by the company as the $\mathrm{CR}$ to be promoted.

Next, as observed in Table 13, the order ranking for the normalized absolute importance of DSs from customer perspectives and company perspectives is the same, which is $\mathrm{DS}_{3}>\mathrm{DS}_{4}>\mathrm{DS}_{2}>\mathrm{DS}_{1}>\mathrm{DS}_{7}>\mathrm{DS}_{5}>\mathrm{DS}_{6}$. This is validated by the sensitivity analysis results, where the customer-stakeholder importance index, $\beta$ (e.g. $\beta=0$, $\beta=0.4$ and $\beta=1$ ) is varied while observing for any ranking changes (see Table 15). It was found that varying $\beta$ value does not influence the ranking order of DSs. This

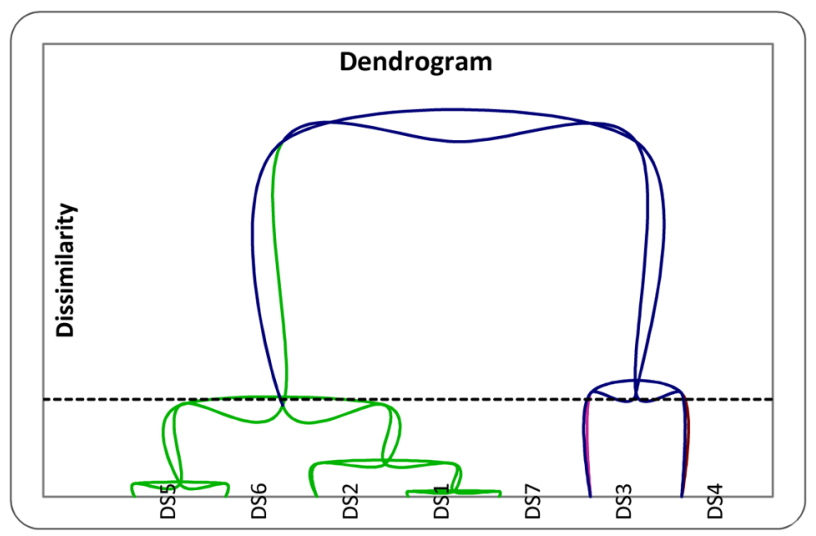

Fig. 4. Hierarchy clustering dendrogram 
Table 15. Changes of final importance of DS for different $\beta$ value

\begin{tabular}{lcccccccc}
\hline & $\beta=0$ & Rank & $\beta=0.4$ & Rank & $\beta=0.7$ & Rank & $\beta=1$ & Rank \\
\hline $\mathrm{DS}_{1}$ & 0.113 & 4 & 0.113 & 4 & 0.112 & 4 & 0.112 & 4 \\
$\mathrm{DS}_{2}$ & 0.128 & 3 & 0.128 & 3 & 0.128 & 3 & 0.127 & 3 \\
$\mathrm{DS}_{3}$ & 0.277 & 1 & 0.275 & 1 & 0.273 & 1 & 0.272 & 1 \\
$\mathrm{DS}_{4}$ & 0.215 & 2 & 0.216 & 2 & 0.216 & 2 & 0.217 & 2 \\
$\mathrm{DS}_{5}$ & 0.083 & 6 & 0.084 & 6 & 0.084 & 6 & 0.085 & 6 \\
$\mathrm{DS}_{6}$ & 0.076 & 7 & 0.077 & 7 & 0.077 & 7 & 0.078 & 7 \\
$\mathrm{DS}_{7}$ & 0.109 & 5 & 0.109 & 5 & 0.109 & 5 & 0.110 & 5 \\
\hline
\end{tabular}

indicates that the customer perspective and company perspective of the assessment are in agreement.

Furthermore, to reduce the large number of alternatives, cluster analysis was applied to segregate the weights records into different categories. From the results of hierarchy clustering, $\mathrm{DS}_{3}$ and $\mathrm{DS}_{4}$ are classified in the category of highly important and moderate respectively. Thus, the company should pay more attention in these 2 designs as compared to the others. The design of $\mathrm{DS}_{5}$ and $\mathrm{DS}_{6}$ can be eliminated since the importance weights are less than 1. As a result, this classification provides the company with the information regarding which design specification group should be focused and eliminated for profit optimization, time and energy savings as well as customer satisfaction.

\section{Conclusions}

In this study, we presented an integrated method of quality function deployment (QFD) and fuzzy analytic network approach (FANP) to evaluate the green buildings. QFD is a tool that can be used to ensure the voice of customers are satisfied by producing the new product (i.e. green building) or improved the current building to better green building index (GBI) rating, as well as to minimize the cost of failure of the company. The proposed methodology allows developers and contractors (acting as a QFD team) to work out the details at the outset, and this eventually promotes a set of technical specifications to better meet customer expectations. Given that the interaction between developers and contractors are continuous throughout the building phase, many aspects of the technical specifications may achieve its desired effect if one considers each activity separately but not when it is integrated. For example, when designing a sustainable building, one of the elements may be to account for more greenery space. One suggestion as a result of this could be to implement green roofing or vegetation roofing if the building is located in a highly priced city where there is no ground space available for such endeavour. This form of roofing acts as an insulation to reduce the heat island effect and it meets the customer's requirements. Yet, to translate this into technical specification, a standard roofing structure could not be used as the new design should account for the extra weight. In the simple scor- ing mechanism for green building assessments, scores are given based on fulfilment of the criterion. However, the feasibility of implementation is not taken into account with the design challenges being worked after-the-fact, thus increasing the cost and leading one to believe that such green pursuit is costly. In order to prevent such issues, our method allows the complexity and challenges to be communicated transparently across both design and technical aspects in the green building assessment. This allows building contractors to be able to tie in the design to the existing technical framework, while the developers and customers will be comfortable knowing that the design expectations are met.

\section{Acknowledgements}

The first two authors would like to express their gratitude to Universiti Sains Malaysia for supporting this research under short term grant No. 304 / PMATHS / 6313071.

\section{References}

Akao, Y.; Mazur, G. H. 2003. The leading edge in QFD: past, present and future, International Journal of Quality \& Reliability Management 20(1): 20-35. http://dx.doi.org/10.1108/02656710310453791

Ali, H. H.; Al Nsairat, S. F. 2009. Developing a green building assessment tool for developing countries - case of Jordan, Building and Environment 44(5): 1053-1064. http://dx.doi.org/10.1016/j.buildenv.2008.07.015

Balachandra, P.; Ravindranath, D.; Ravindranath, N. H. 2010. Energy efficiency in India: assessing the policy regimes and their impacts, Energy Policy 38(11): 6428-6438. http://dx.doi.org/10.1016/j.enpol.2009.08.013

Behzadian, M.; Hosseini-Motlagh, S. M.; Ignatius, J.; Goh, M.; Sepehri, M. M. 2013. PROMETHEE group decision support system and the house of quality, Group Decision and Negotiation 22(2): 189-205. http://dx.doi.org/10.1007/s10726-011-9257-3

Bourdeau, L. (Ed.). 1999. Agenda 21 on sustainable construction. CIB Report Publication 237. CIB. Rotterdam.

Büyüközkan, G.; Cifci, G. 2012. A new incomplete preference relations based approach to quality function deployment, Information Sciences 206: 30-41. http://dx.doi.org/10.1016/j.ins.2012.04.010

Büyüközkan, G.; Feyzioğlu, O.; Ruan, D. 2007. Fuzzy group decision-making to multiple preference formats in quality function deployment, Computers in Industry 58(5): 392-402. http://dx.doi.org/10.1016/j.compind.2006.07.002 
Chan, L.-K.; Wu, M. L. 2002. Quality function deployment: a literature review, European Journal of Operational Research 143(3): 463-497. http://dx.doi.org/10.1016/S0377-2217(02)00178-9

Chua, S. C.; Oh, T. H. 2011. Green progress and prospect in Malaysia, Renewable and Sustainable Energy Reviews 15(6): 2850-2861. http://dx.doi.org/10.1016/j.rser.2011.03.008

Chin, K. L. 2005. Major challenges in protecting biodiversity, New Straits Times, 25 January 2005.

Csutora, R.; Buckley, J. J. 2001. Fuzzy hierarchical analysis: the Lambda-Max method, Fuzzy sets and Systems 120(2): $181-195$. http://dx.doi.org/10.1016/S0165-0114(99)00155-4

Darus, Z. M.; Hashim, N. A.; Salleh, E.; Haw, L. C.; Rashid, A. K. A.; Manan, S. N. A. 2009. Development of rating system for sustainable building in Malaysia, WSEAS Transactions on Environmental Problems and Development 5(3): 261-272.

Dixit, M. K.; Fernandez-Solis, J. L.; Lavy, S.; Culp, C. H. 2010. Identification of parameters for embodied energy measurement: a literature review, Energy and Buildings 42(8): $1238-1247$. http://dx.doi.org/10.1016/j.enbuild.2010.02.016

Du Plessis, C. 2007. A strategic framework for sustainable construction in developing countries, Construction Management and Economics 25(1): 67-76. http://dx.doi.org/10.1080/01446190600601313

Ertay, T.; Büyüközkan, G.; Kahraman, C.; Ruan, D. 2005. Quality function deployment implementation based on analytic network process with linguistic data: an application in automotive industry, Journal of Intelligent \& Fuzzy Systems: Applications in Engineering and Technology 16(3): 221-232.

Green Building Index Malaysia (GBI). 2009 [online], [cited 25 October 2015]. Available from Internet: http://www.greenbuildingindex.org/

Hwang, B. G.; Tan, J. S. 2012. Green building project management: obstacles and solutions for sustainable development, Sustainable Development 20(5): 335-349. http://dx.doi.org/10.1002/sd.492

Ignatius, J.; Motlagh, S. M. H.; Sepehri, M. M.; Behzadian, M.; Mustafa, A. 2010. Hybrid models in decision making under uncertainty: the case of training provider evaluation, Journal of Intelligent \& Fuzzy Systems: Applications in Engineering and Technology 21(1, 2): 147-162.

Ignatius, J.; Mustafa, A.; Goh, M. 2012. Modeling funding allocation problems via AHP-fuzzy TOPSIS, International Journal of Innovative Computing, Information and Control 8(5A): 3329-3340.

Juan, Y.-K.; Gao, P.; Wang, J. 2010. A hybrid decision support system for sustainable office building renovation and energy performance improvement, Energy and Buildings 42(3): 290-297. http://dx.doi.org/10.1016/j.enbuild.2009.09.006

Kabak, M.; Kose, E.; Kirilmaz, O.; Burmaoglu, S. 2014. A fuzzy multi-criteria decision making approach to assess building energy performance, Energy and Buildings 72: 382-389. http://dx.doi.org/10.1016/j.enbuild.2013.12.059

Kahraman, C.; Ertay, T.; Büyüközkan, G. 2006. A fuzzy optimization model for QFD planning process using analytic network approach, European Journal of Operational Research 171(2): 390-411. http://dx.doi.org/10.1016/j.ejor.2004.09.016

Karsak, E. E.; Sozer, S.; Alptekin, S. E. 2003. Product planning in quality function deployment using a combined analytic network process and goal programming approach, Computers \& Industrial Engineering 44(1): 171-190. http://dx.doi.org/10.1016/S0360-8352(02)00191-2

Kwok, A. G.; Rajkovich, N. B. 2010. Addressing climate change in comfort standards, Building and Environment 45(1): 18-22. http://dx.doi.org/10.1016/j.buildenv.2009.02.005
Lee, W. L.; Burnett, J. 2008. Benchmarking energy use assessment of HK-BEAM, BREEAM and LEED, Building and Environment 43(11): 1882-1891. http://dx.doi.org/10.1016/j.buildenv.2007.11.007

Lin, C. J.; Wu, W. W. 2008. A causal analytical method for group decision-making under fuzzy environment, Expert Systems with Applications 34(1): 205-213. http://dx.doi.org/10.1016/j.eswa.2006.08.012

Liu, H.-T.; Wang, C.-H. 2010. An advanced quality function deployment model using fuzzy analytic network process, Applied Mathematical Modelling 34(11): 3333-3351. http://dx.doi.org/10.1016/j.apm.2010.02.024

Lockwood, C. 2006. Building the green way, Harvard Business Review 84(6): 129-137.

Menassa, C. C.; Baer, B. 2014. A framework to assess the role of stakeholders in sustainable building retrofit decisions, Sustainable Cities and Society 10: 207-221. http://dx.doi.org/10.1016/j.scs.2013.09.002

Motlagh, S. M. H.; Behzadian, M.; Ignatius, J.; Goh, M.; Sepehri, M. M.; Hua, T. K. 2015. Fuzzy PROMETHEE GDSS for technical requirements ranking in HOQ, The International Journal of Advanced Manufacturing Technology 76(9): 1993-2002. http://dx.doi.org/10.1007/s00170-014-6233-5

Murakami, S.; Kawakubo, S.; Asami, Y.; Ikaga, T.; Yamaguchi, N.; Kaburagi, S. 2011. Development of a comprehensive city assessment tool: CASBEE-City, Building Research \& Information 39(3): 195-210.

http://dx.doi.org/10.1080/09613218.2011.563920

National Energy Research Laboratory (NREL). 2006. Lessons learned from case studies of six high-performance buildings. Technical report No. NREL/TP-550-37542. U.S. Department of Energy, Office of Energy Efficiency and Renewable Energy.

Ries, R.; Bilec, M. M.; Gokhan, N. M.; Needy, K. L. 2006. The economic benefits of green buildings: a comprehensive case study, The Engineering Economist 51(3): 259-295. http://dx.doi.org/10.1080/00137910600865469

Saaty, T. 1996. Decision making with dependence and feedback: the analytic network process. Pittsburgh: RWS Publications. 370 p.

Šaparauskas, J. 2003. Multiple criteria evaluation of buildings with emphasis on sustainability, Journal of Civil Engineering and Management 9(4): 234-240. http://dx.doi.org/10.1080/13923730.2003.10531334

Wang, W.; Zmeureanu, R.; Rivard, H. 2005. Applying multiobjective genetic algorithms in green building design optimization, Building and Environment 40(11): 1512-1525. http://dx.doi.org/10.1016/j.buildenv.2004.11.017

Wong, W. P.; Ignatius, J.; Soh, K. L. 2014. What is the leanness level of your organisation in lean transformation implementation? An integrated lean index using ANP approach, Production Planning \& Control 25(4): 273-287. http://dx.doi.org/10.1080/09537287.2012.674308

Wu, W. W.; Lee, Y. T. 2007. Developing global managers' competencies using the fuzzy DEMATEL method, Expert Systems with Applications 32(2): 499-507. http://dx.doi.org/10.1016/j.eswa.2005.12.005

Yeap, J. A.; Ignatius, J.; Ramayah, T. 2014. Determining consumers' most preferred eWOM platform for movie reviews: a fuzzy analytic hierarchy process approach, Computers in Human Behavior 31: 250-258. http://dx.doi.org/10.1016/j.chb.2013.10.034

Zadeh, L. A. 1975. The concept of a linguistic variable and its application to approximate reasoning-I, Information Sciences 8(3): 199-249. http://dx.doi.org/10.1016/0020-0255(75)90036-5 
Joshua IGNATIUS. He is an Associate Professor of Operations Research at the School of Mathematical Sciences, Universiti Sains Malaysia. His research is transdisciplinary and focuses on resource allocation and performance evaluation models across a variety of industries. He has published in numerous high impact SCI/SSCI journals such as European Journal of Operational Research, TECHNOVATION, Knowledge Based Systems, Journal of Intelligent \& Fuzzy Systems, Experts Systems with Applications, and Group Decision \& Negotiation. Dr J. Ignatius is the recipient of the Endeavour Executive Award for high achieving professionals in 2010/11 by the Australian Government under the then Prime Minister Julia Gillard's administration.

Amirah RAHMAN. She is a PhD graduate from the University of New South Wales, Australia and currently serving as a Senior Lecturer at the School of Mathematical Sciences, Universiti Sains Malaysia. Her research interest is in Discrete Optimization. She is actively pursuing advancement of mathematical applications across various industries; in particular, transportation and construction.

Morteza YAZDANI. He is a PhD scholar in business economic at Universidad Europea de Madrid, Spain. His main research interest is on the application of multi criteria decision making in various fields such as material science, supply chain management and strategic planning. He has published in some international journals, e.g. International Journal of Strategic Decision Sciences, Expert Systems with Applications, Materials \& Design, and International Journal of Logistics Research.

Jonas ŠAPARAUSKAS. He is an Associate Professor at the Department of Construction Technology and Management, and Vicedean of undergraduate studies of the Faculty of Civil Engineering of Vilnius Gediminas Technical University. Dr J. Šaparauskas is a member of EURO Working Group - OR in Sustainable Development and Civil Engineering (EWG-ORSDCE). He has authored more than 20 scientific articles and 1 book. His research interests are in construction technology and organisation, construction investments management, multiple criteria decision making, sustainable development.

Syarmila Hany HARON. She is a senior lecturer in interior design at the School of Housing, Building and Planning, Universiti Sains Malaysia. Her research interests are in sustainable design and urban planning, including crime prevention. She has won several design awards in Malaysia. 